\title{
A Preliminary Study: The Influence of Alkali Treatment on Physical and Mechanical Properties of Coir Fiber
}

\author{
R. Hari Setyanto ${ }^{1}$, Kuncoro Diharjo ${ }^{2}$, I. Made Miasa ${ }^{3} \&$ Prabang Setyono $^{4}$ \\ ${ }^{1}$ Department of Industrial Engineering, Sebelas Maret University, Surakarta City, Central Java, Indonesia \\ ${ }^{2}$ Department of Mechanical Engineering, Sebelas Maret University, Surakarta City, Central Java, Indonesia \\ ${ }^{3}$ Department of Mechanical and Industrial Engineering, Gadjah Mada University, Yogyakarta City, Indonesia \\ ${ }^{4}$ Department of Environmental Science, Sebelas Maret University, Surakarta City, Central Java, Indonesia \\ Correspondence: R. Hari Setyanto, Department of Industrial Engineering, Sebelas Maret University, Surakarta \\ City, Central Java, Indonesia. Tel: 62-812-2982-6777. E-mail: hstyan97@gmail.com
}

\author{
Received: August 27, 2013 Accepted: September 11, 2013 Online Published: September 23, 2013 \\ doi:10.5539/jmsr.v2n4p80 URL: http://dx.doi.org/10.5539/jmsr.v2n4p80
}

\begin{abstract}
This research was conducted to analyze the alkali treatment in improving the quality of coir fiber. Study coir fiber done by specifying the physical characteristics and methods of making specimen, mechanical treatment and testing the tensile strength of single fiber. Determine the characteristics physical of the fiber is done by observing and measuring the diameter of the fiber directly, testing the density and moisture content testing. Chemical treatment is done by the method of alkali. Single coir fibers for the treatment carried out using $\mathrm{NaOH} 5 \%$. Alkali solution set with a variation of the submersion of $0,1,2,3$, and 4 hours. Single fiber tensile strength testing is done according to standard ASTM C1557-2003. Tensile tests showed that an alkali treatment can increase the tensile strength of single fiber of $27.9 \%$ in immersion lye for 2 hours compared without soaking and increase the elongation of over $20 \%$ compared without soaking.
\end{abstract}

Keywords: coir fiber, alkali treatment, tensile strength, elongation

\section{Introduction}

In recent years, the results of research in the field of fiber-reinforced composite developed nature for use in some application properties (Vieira et al., 2009; Idicula et al., 2006), because it has a low density, small fee/cheap and biodegradable capability is a relevant characteristic in selecting materials of natural fibers as reinforcement (Joshi et al., 2004; Ahmed et al., 2007).

Natural fibers are very attractive treatment for studied because it is possible to design composite has a mechanical performance that meets the needs of the product. The benefits of replacing the natural fibers are synthetic fibers will reduce environmental problems especially on the problems of ecology because of natural fibers can be recycled through thermal recycling. In addition to natural fibers are fibers that can be updated and lighter than synthetic fibers (Vieira et al., 2009). The use of natural fibers that are very abundant in Indonesia will also bring economic and social benefits.

The next problem that arises is "how increasing the tensile strength of single fiber?" According to some sources the literature/libraries, increased tensile strength fibers of nature can be done in two ways, namely by providing treatment of chemical fiber or by adding coupling agent (Diharjo et al., 2005). Treatment of chemical fibers are often performed is the treatment of alkali as $\mathrm{NaOH}$, because it is more economical.

The description indicates that the fiber has a huge potential for use in engineering, particularly as the amplifier composite materials. The mechanical properties of the composite can be improved by treatment of alkali $(\mathrm{NaOH})$ and soaking the fibers. The results of this research are expected to inspire researchers to examine further the utilization of the various natural fibers as composites reinforcement. In this study, an evaluation of the nature of the fiber was developed through a process of analysis of the tensile properties of coir fiber. 


\section{Material and Method}

\subsection{Material}

Coir fiber obtained from Surakarta, Indonesia and surrounding areas. Coir fiber which still contains lignin and dirt is cleaned using water. Clean fiber soaked in lye $(\mathrm{NaOH} 5 \%)$ with a variation of time soaking $0,1,2$, 3, and 4 hours. Next the fiber of the effect is neutralized with $\mathrm{NaOH}$ soaking using clean water. After the neutral $\mathrm{pH}$ of the marinade $(\mathrm{pH}=7)$, fiber is then dried without sunlight or dried at room temperature.

\subsection{Characterization}

\subsubsection{Determination of the Diameter of the Fiber}

Fiber diameter of 150 samples measured at maximum and minimum diameter of each fiber, as an illustration for the measurement of fiber diameter can be seen in Figure 1.

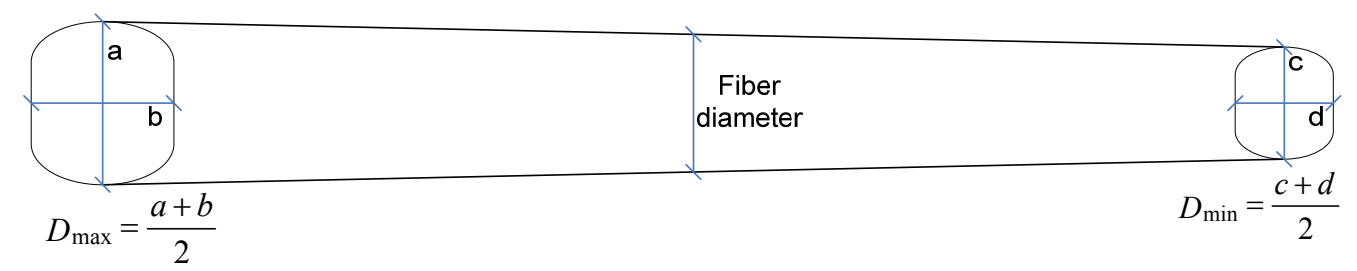

Figure 1. Illustration coir fiber diameter measurement

Next will be known coir fiber diameter by the equation:

$$
\text { Fiber } \text { diameter }=\frac{\text { Diameter }_{\text {max }}+\text { Diameter }_{\text {min }}}{2}
$$

The Data is grouped by frequency distribution class. The determination of the amount of the frequency distribution classes determined using the rules of Sturges, then the equation:

$$
C=1+3.3 \log N
$$

where $C$ is the class frequency distribution, whereas $N$ is the number of data

Size class distribution of intervals using the equation:

$$
\text { Size class distribution }=\frac{\text { Distribution range }}{\text { The number of class intervals }} \text { or } \frac{\text { Distribution range }}{1+3.3 \log N}
$$

results from Equations (2) and (3) above, then make the frequency distribution coir fibers diameter and then will know the value of fiber diameter ranges used in the study.

\subsubsection{Testing Moisture Content of Coir Fibers}

Test of coir fiber water content at fiber without treatment of alkali on the wet and dry conditions. Test the moisture content is done by heating about $2-3$ grams fiber coir in the oven at a temperature of $100^{\circ} \mathrm{C}$. To find out where the water levels, these fibers are weighted with digital scales are periodic.

\subsubsection{Single Fiber Tensile Test}

Single fiber tensile testing based on ASTM C1557-03, tensile testing was performed in the laboratory materials Faculty of Mechanical Engineering Sebelas Maret University, Surakarta, Indonesia with fiber tensile tester Tenso LAB. Fiber tensile test samples are shown in Figure 2. 


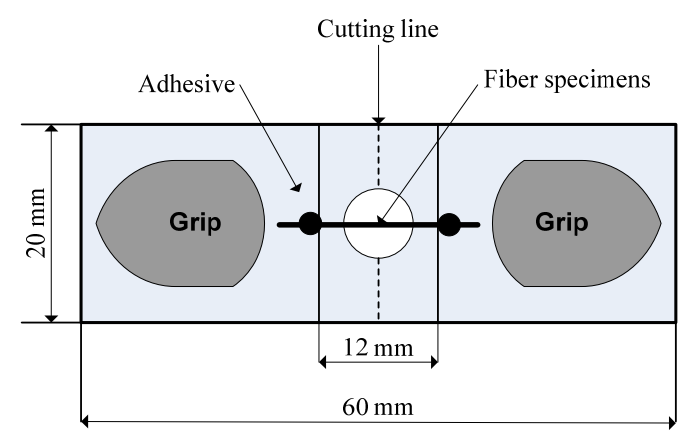

Figure 2. Single fiber tensile test specimens (ASTM C1557, 2003)

The tensile properties of carbon fibers samples were determined using a single filament tensile test, according to ASTM C1557 Standard. The testing machine used during this work was DMA Q800-TA Instruments and the force rate used was $0.150 \mathrm{~N} / \mathrm{min}$.

The filaments were carefully separated from the carbon fiber tow and then mounted on a support tab as shown in Figure 1. Extreme care was taken to ensure that the filament was aligned axially with the tensile direction. Prior to the test, the support tab was cut at the sides of the hole, leaving two pieces of paper with the filament endings glued on them (only the filament between the grips).

The tensile strength is obtained from the ratio of the peak force to the cross sectional area of a plane perpendicular to the fiber axis (Equation (2)):

$$
\sigma=\frac{F}{A}
$$

where $\mathrm{F}$ is a force to failure, $\mathrm{N}$; $\mathrm{A}$ is fiber cross-sectional area at fracture plane, $\mathrm{m}^{2}$

The coir fiber Young's modulus was calculated following the procedure described in the ASTM C1557 Standard. Tensile tests were performed using different gauge lengths $(12 \mathrm{~mm})$. For each test, the force versus cross-head displacement curve was constructed. From the curve, the inverse of the slope of the initial linear region was obtained in $\mathrm{m} / \mathrm{N}$. By combining the Equations (4), (5), (6) and (7), we obtain Equation (8), as follows:

$$
\begin{gathered}
\varepsilon=\frac{\Delta l}{l_{0}} \\
\Delta L=\Delta l+C_{s} F \\
\sigma=E \varepsilon \\
\varepsilon=\frac{\sigma}{E}=\frac{F}{E A}=\frac{\Delta l}{l_{0}}
\end{gathered}
$$

where $\varepsilon$ is strain, $\Delta l$ is elongation of the gauge length, $\mathrm{m} ; l_{0}$ is gauge length, $\mathrm{m} ; \Delta L$ is recorded cross-head displacement, $\mathrm{m} ; C_{s}$ is system compliance, $\mathrm{m} / \mathrm{N} ; E$ is Young's modulus.

The combination of Equations (6) and (8) leads to the Equation (9):

$$
\frac{\Delta L}{F}=\frac{\Delta l}{F}+C_{s}=\frac{l_{0}}{E A}+C_{s}
$$

Therefore, a plot of $(\Delta L / F)$ versus $\left(l_{0} / A\right)$ will yield a straight line with the constant slope of $1 / E$, as it is shown in Figure 3. 


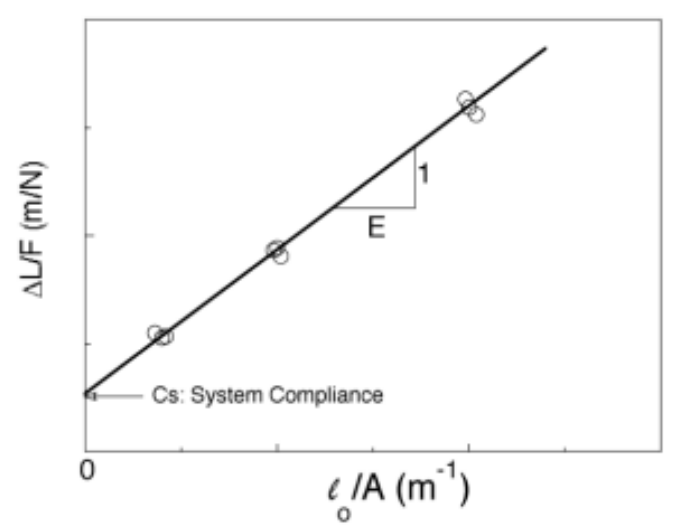

Figure 3. Method for determining the Young's modulus (ASTM C1557, 2003)

\subsubsection{Scanning Electron Microscopy (SEM)}

Specimens/fiber without and with treatment, fiber surface morphology was observed using Scanning Electron Microscopy (SEM) at different resolutions.

\section{Results and Discussion}

\subsection{Determination of Coir Fiber Diameter}

The fiber contained in coir various diameter, so the need for determining the diameter of the fiber to be used in research. Coir fiber diameter diversity was examined by some researchers that the diameter of the coir fiber between 0.10-0.40 mm (Aggarwal, 1992; Ramakrishna \& Sundararajan, 2005; Reis, 2006), while in the course Satyanarayana et al. (1990) states that the diameter of the fiber between $0.10-0.45 \mathrm{~mm}$.

As many as 150 samples of the selected fiber diameter is between $92-314 \mu \mathrm{m}(0.092-0.314 \mathrm{~mm})$, of 150 samples were grouped into intervals class as much as 9 class. Frequency distribution of diameter of coir fibers can be seen in Figure 4.

Frequency distribution of coir fiber diameter showed that the interval $165-190 \mu \mathrm{m}$ have as many as 78 samples of data, it shows that the average diameter of the fiber is located between $165-190 \mu \mathrm{m}$. If the statistically calculated average fiber diameter was $182.82 \pm 36.31 \mu \mathrm{m}$, this showed that the average diameter of the fibers actually lies in the interval, so in this study will be selected fiber diameter between 165-190 $\mu \mathrm{m}$. The purpose of the grouping interval class in order to obtain a single fiber tensile strength values are uniform.

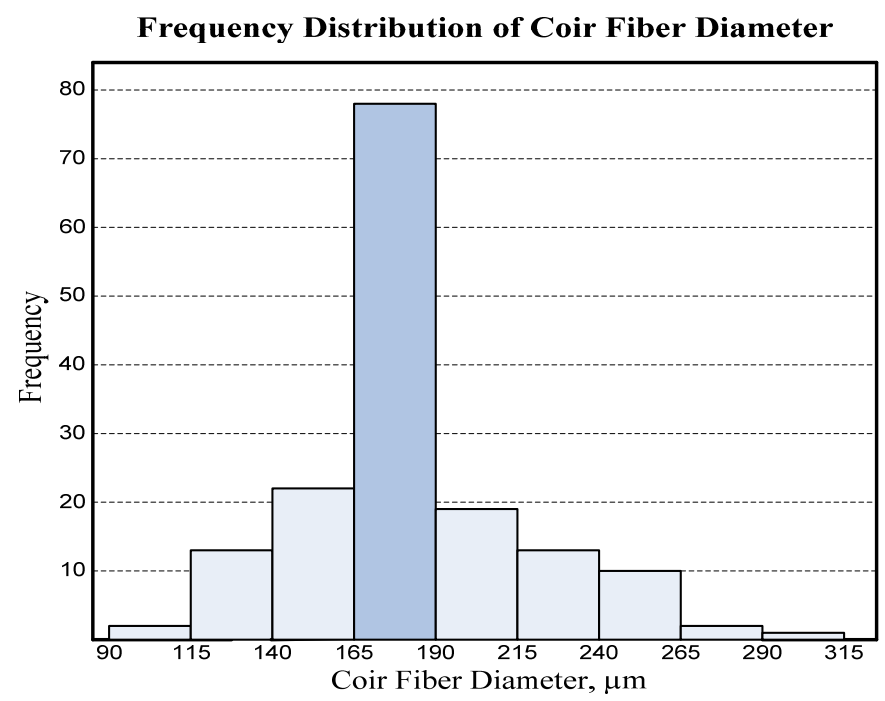

Figure 4. Frequency distribution of coir fiber diameter 


\subsection{The Density of Coir Fiber}

Data on the test results of coir fibers based on standard ASTM D3800, shows that the conditions of moisture content of $0 \%$ of the fiber is $0.814 \mathrm{~g} / \mathrm{cm}^{3}$. Results of research conducted by some researchers, that is, Ayrilmis et al. (2011) concluded that the mass of coir fiber is $0.9 \mathrm{~g} / \mathrm{cm}^{3}$, Malkapuram et al. (2009) are $1.15 \mathrm{~g} / \mathrm{cm}^{3}$, and Ali (2011) was $0.67-1.00 \mathrm{~g} / \mathrm{cm}^{3}$. Analysis of the comparisons of the results of this research with the results of earlier research showed that the density of fiber coir $\left(0.814 \mathrm{~g} / \mathrm{cm}^{3}\right)$ have a very close third results of earlier researchers.

If paying attention to Figure 5, the decline of fibers that are alkali $(\mathrm{NaOH})$ treatments can be caused due to loss of hemicellulose, lignin, wax, grease, and grime from the surface of the fiber. As a result, the primary cell walls of fiber damage and cause a decrease in the total weight of the fiber, so the core will result in the loss of fiber, in addition, decline of fiber can also be caused by the increase of porosity in fiber (Wong et al., 2010). Research conducted Munawar et al. (2008), States that the fibers are alkali treatment led to the separation of the fiber bundle, which is an indication that the structure of the bundle to be porous, while Mwaikambo and Ansell (2006) also mentioned that the fibers are alkali treatment will cause damage to the cellulose in the fiber. Alkali treatment can eliminate the lignin, pectin, hemicellulose, ash, and resulted in some of the extraction process, which is the main cause of the decrease in density fiber (Suardana et al., 2011).

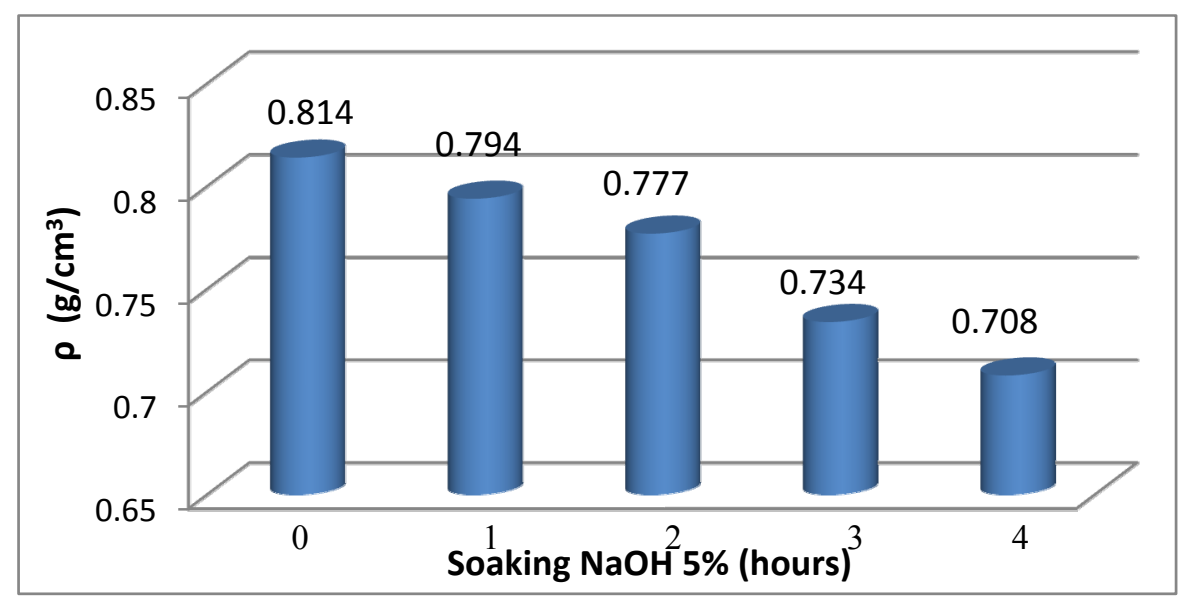

Figure 5. Effects of alkali soaking on the coir fiber density

\subsection{Coir Fiber Tensile Strength}

To make it easier to perform analysis of the influence of alkali treatment on tensile properties of coir fiber then the data displayed in the form of the curve is the relationship between tensile properties of fiber coir against alkaline treatment duration, as shown in Figure 6.

Results of this study indicate that the alkali treatment lowers the tensile strength of the fiber in 1 hour immersion, but immersion time increased tensile strength 2 , then at 3 and 4 hours of immersion decreased, as shown in Figure 7. In the alkali treatment of fibers, showed that fiber soaking for 2 hours yield the most optimal tensile strength. In this condition a result of the effect of elongation of the fiber so that the fiber tensile strength increased, then 3 and 4 hours soaking decreased the tensile strength is due to the damaging effect of alkali treatment of fibers. The results by Sgriccia et al. (2008) indicate that the alkali treatment removes hemicellulose and lignin from natural fiber surface, this suggests that the content of hemicellulose and lignin will erode the significance of treatment within 2 hours of alkali $(5 \% \mathrm{NaOH})$ and $\alpha$-cellulose component also decreased slowly (Ray et al., 2001), while Rosa et al. (2009) stated that the alkali treatment can increase the tensile strength of approximately 53\% compared to the untreated fiber. Comparison of these results with the results of the study Sgriccia et al. (2008), Ray et al. (2001), and Rosa et al. (2009) concluded that soaking the fiber will eliminate hemicellulose and lignin in the number and erode the significance of gamma and beta cellulose, alpha cellulose consequently can improve the properties elongation/maximum strain thus providing optimum tensile strength properties. This is considered a very rational reason for $\alpha$-cellulose fiber is a key element. 


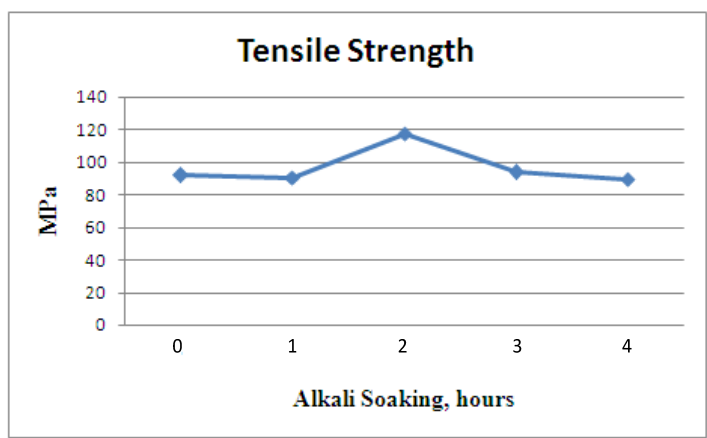

a. Tensile strength

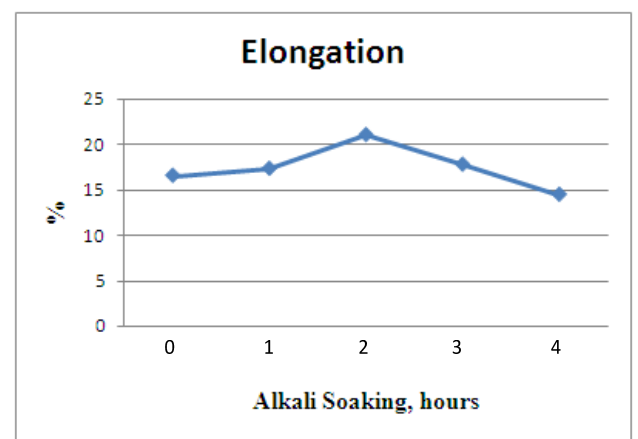

b. Elongation

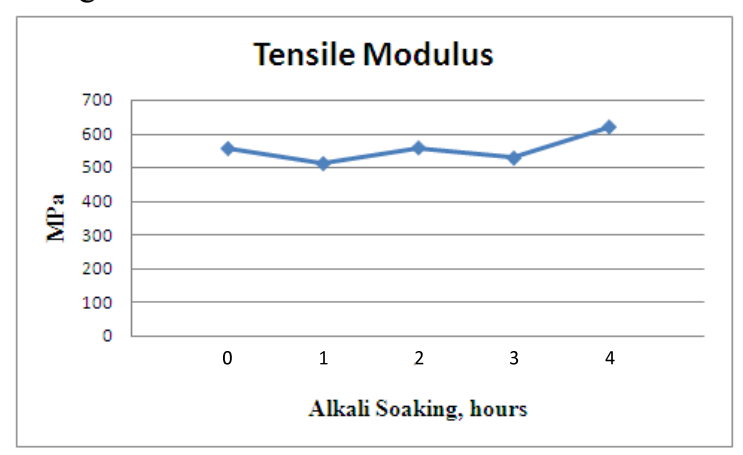

c. Tensile modulus

Figure 6. Curva of coir fiber tensile properties due to alkali treatment

Statistical analysis (T-test) showed that the test results show the 2-hour immersion has the largest tensile strength values than without and with immersion, while soaking $0,1,3$, and 4 hours there was no difference in the value of the tensile test. Table 1 shows the results of statistical analysis (T-test).

Table 1. T-test tensile strength of coir fiber (level of confidence 95\%)

\begin{tabular}{ccccc}
\hline No & Versus & $\mathbf{P}_{\text {value }}$ & $\mathbf{P}_{\text {value }}<\boldsymbol{\alpha}$ & Decision \\
\hline 1 & 0 vs 1 & 0.792 & No & No difference \\
2 & 0 vs 2 & 0.011 & Yes & Difference \\
3 & 0 vs 3 & 0.423 & No & No difference \\
4 & 0 vs 4 & 0.333 & No & No difference \\
5 & 1 vs 2 & 0.011 & Yes & Difference \\
6 & 1 vs 3 & 0.574 & No & No difference \\
7 & 1 vs 4 & 0.909 & No & No difference \\
8 & 2 vs 3 & 0.014 & Yes & Difference \\
9 & 2 vs 4 & 0.009 & Yes & Difference \\
10 & 3 vs 4 & 0.187 & No & No difference \\
\hline
\end{tabular}

\subsection{Effects of Alkali Treatment on the Surface of the Coir Fiber}

Figure 7a shows a SEM of coir fibers alkali untreated. Look at the picture that the bundle of fiber does not appear because it is still tied and coated by natural fiber matrix (lignin, pectin, and candles) in fiber (Islam et al., 2005), because the primary role of lignin is forming a layer the 2 fibers that serve as binding between fiber cellulose in wood or non-wood. It is the same as that presented by Carvalho et al. (2010) indicates that the coir fiber surface covered by a layer of substances such as oils, waxes, and extractives, part of the natural constitution 
of lignocellulosic fibers.

Figure $7 \mathrm{~b}$ shows the SEM of alkali soaking treatment for 2 hours. Alkali treatment to remove fat and cuticle that will eventually form the holes and rough surfaces, so it will give better mechanical properties. However, when carefully considered, the SEM showed that soaking the fiber for 2 hours showed that lignin and hemicellulose layer has thinned due to degraded due to dissolved by alkaline fluid, and fiber bundles visible stuff. This is a bundle of cellulose fiber core which consists of alpha, gamma and beta cellulose, but the effect of alkali soaking for 2 hours resulted in beta and gamma cellulose eroded. Among the three cellulose, $\alpha$-cellulose is a fibrous substance, which has a high tensile stress, is not soluble in water, and insoluble by organic solvents. Therefore, the loss of gamma and beta cellulose will provide optimal fiber elongation properties, so that the fiber tensile strength will increase. Similar results were also observed by Bismarck et al. (2001), Choudhury et al. (2007), Rahman and Khan (2007), and Rout et al (2001) who said that the alkali treatment would result in surface exposure of crude fiber and will increase the value of mechanical fiber.

Figure 7c, an SEM of fiber immersion in an alkaline solution for 3 hours. On immersion is seen that the bundles of fibers ranging fragile due to begin erosion of $\alpha$-cellulose, which in turn will affect/reduce the tensile strength of fiber.

Figure 7d, shows the SEM of the fiber lye soaked for 4 hours. On the fibers appear white layer and cuticle holes visible thinning effect of chain polymerization is terminated, so the lye began to erode $\alpha$-cellulose fiber thus experiencing fragility resulting from $\alpha$-cellulose content decreased.

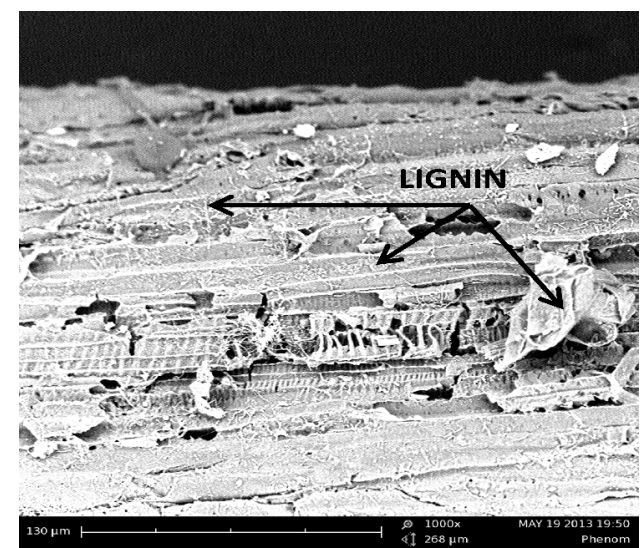

a. Untreated (SEM 1000x)

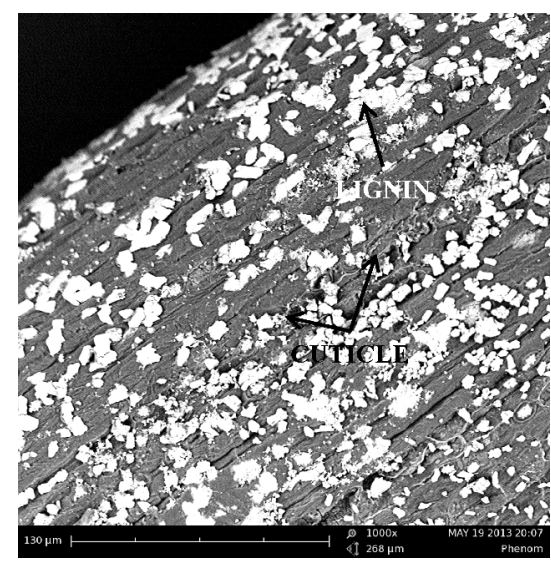

c. Alkali treatment ( $\mathrm{NaOH} 5 \%, 3 \mathrm{hr})(\mathrm{SEM} 1000 \mathrm{x})$

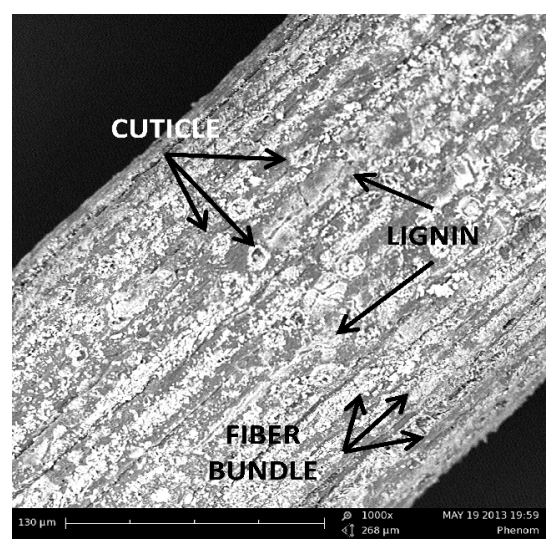

b. Alkali treatment ( $\mathrm{NaOH} 5 \%, 2 \mathrm{hr})$ (SEM 1000x)

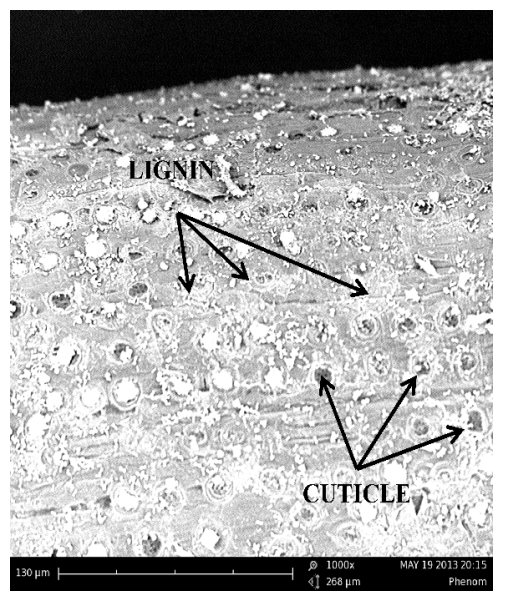

d. Alkali treatment ( $\mathrm{NaOH} 5 \%, 4 \mathrm{hr})$ (SEM 1000x)

Figure 7. SEM of coir fibers

\section{Conclusion}

The purpose of this study was to determine whether the material is fit for use coconut fiber as a composite 
reinforcement, tensile strength, tensile modulus and elongation of fiber will be tested in this study. Results are summarized as follows:

1) The purpose of the grouping interval class in order to obtain a single fiber tensile strength values are uniform. Coir fiber diameter were used in testing the tensile strength is $165-190 \mu \mathrm{m}$.

2) Alkali treatment tends to reduce the density of the fiber due to the loss of hemicellulose, lignin, wax, grease, and dirt from the surface of the fiber so that it will lead to lower fiber density, but alkali treatment can also improve the tensile strength of a single coir fiber. On the other hand, the elongation of single coir fiber also had a tendency to rise.

3) Increase in tensile strength at the optimum alkali immersion treatment for 2 hours. The ability of a single fiber in the tensile load and elongation received respectively at $117.36 \mathrm{MPa}$ and above $20 \%$. Treatment duration of fiber arrangement immersion into the alkali solution will affect the quality of coir fiber, both tensile strength and elongation.

\section{References}

Ahmed, K. S., Vijayarangan, S., \& Naidu, A. C. B. (2007). Elastic properties, notched strength and fracture criterion in untreated woven jute-glass fabric reinforced polyester hybrid composites. Materials \& Design, 28(8), 2287-2294. http://dx.doi.org/10.1016/j.matdes.2006.08.002

Ali, M. (2011). Coconut fibre: A versatile material and its applications in engineering. Journal of Civil Engineering and Construction Technology, 2(9), 189-197

Anggarwal, L. K. (1992). Studies on cement-bonded coir fibre boards. Cement and Concrete Composites, 14(1), 63-69. http://dx.doi.org/10.1016/0958-9465(92)90040-3

ASTM C 1557. (2003). Standard Test Method for Tensile Strength and Young's Modulus of Fibers.

Ayrilmis, N., Jarusombuti, S., Fueangvivat, V., Bauchongkol, P., \& White, R. H. (2011). Coir fiber reinforced polypropylene composite panel for automotive interior applications. Journal of Fibers and Polymers, 12(7), 919-926. http://dx.doi.org/10.1007/s12221-011-0919-1

Bismarck, A., Mohanty, A. K., Aranberri-Askargorta, I., Czapla, S., Misra, M., Hinrichsenb, G., \& Springera, J. (2001). Surface characterization of natural fibers; surface properties and the water up-take behavior of modified sisal and coirfibers. Green Chemistry, 3, 100-107. http://dx.doi.org/10.1039/b100365h

Carvalho, K. C. C., Mulinari, D. R., Voorwald, H. J. C., \& Coffi, M. O. H. (2010). Chemical modification effect on the mechanical properties of hips/coconut fiber composites. BioResources, 5(2), 1143-1155.

Choudhury, A., Kumar, S., \& Adhikari, B. (2007). Recycled milk pouch and virgin lowdensity. Polyethylene/linear low-density polyethylene based coir fiber composites. Journal of Applied Polymer Science, 106(2), 775-785. http://dx.doi.org/10.1002/app.26522

Diharjo, K., Jamasri, Soekrisno, \& Rochardjo, H. S. B. (2005). Tensile Properties of Random kenaf Fiber Reinforced Polyester Composite. National Seminar Proceeding, Center of Inter University, Gadjah Mada University, Yogyakarta, Indonesia.

Idicula, M., Boudenne, A., Umadevi, L., Ibos, L., Candau, Y., \& Thomas, S. (2006). Thermophysical properties of natural fibre reinforced polyester composites. Composites Science and Technology, 66(15), 2719-2725. http://dx.doi.org/10.1016/j.compscitech.2006.03.007

Joshi, S. V., Drzal, L. T., Mohanty, A. K., \& Arora, S. (2004). Are natural fiber composites environmentally superior to glass fiber reinforced composites? Applied Science and Manufacturing, 35(3), 371-376.

Malkapuram, R., Kumar, V., \& Negi, Y. S. (2009). Recent development in natural fiber reinforced polypropylene composites. Journal of Reinforced Plastics and Composites, 28(10), 1169-1189. http://dx.doi.org/10.1177/0731684407087759

Munawar, S. S., Umemura, K., Tanaka, F., \& Kawai, S. (2008). Effects of alkali, mild steam, and chitosan treatments on the properties of pineapple, ramie, and sansevieria fiber bundles. Journal of Wood Science, 54(1), 28-35. http://dx.doi.org/10.1007/s10086-007-0903-y

Mwaikambo, L. Y., \& Ansell, M. P. (2006). Mechanical properties of alkali treated plant fibres and their potential as reinforcement materials II. Hemp fibres. Journal of Materials Science, 41(8), 2483-2496. http://dx.doi.org/10.1007/s10853-006-5075-4 
Rahman, M. M. \& Khan, M. A. (2007). Surface treatment of coir (Cocos nucifera) fibers and its influence on the fibers' physico-mechanical properties. Composites Science and Technology, 67(11-12), 2369-2376. http://dx.doi.org/10.1016/j.compscitech.2007.01.009

Ramakrishna, G., \& Sundararajan, T. (2005). Impact strength of a few natural fibre reinforced cement mortar slabs: A comparative study. Cement and Concrete Composites, 27(5), 547-553. http://dx.doi.org/10.1016/j.cemconcomp.2004.09.006

Reis, J. M. L. (2006). Fracture and flexural characterization of natural fiber-reinforced polymer concrete. Construction and Building Materials, 20(9), 673-678. http://dx.doi.org/10.1016/j.conbuildmat.2005.02.008

Rosa, M. F., Chiou, B., Medeiros, S. S., Wood, D. F., Williams, T. G., Mattoso, L. H. C., ... Imam, S. S. (2009). Effect of fiber treatments on tensile and thermal properties of starch/ethylene vinyl alcohol copolymers/coir $\begin{array}{llll}\text { biocomposites. } & \text { Bioresource } & \text { Technology, } & \text { 100(21), }\end{array}$ http://dx.doi.org/10.1016/j.biortech.2009.03.085

Rout, J., Misra, M., Tripathy, S. S., Nayak, S. K., \& Mohanty, A. K. (2001). The influence of fibre treatment on the performance of coir-polyester composites. Composites Science and Technology, 61(9), 1303-1310. http://dx.doi.org/10.1016/S0266-3538(01)00021-5

Satyanarayana, K. G., Sukumaran, K., Mukherjee, P. S., Pavithran, C., \& Pillai, S. G. K. (1990). Natural Fibre-polymer Composites. Cement and Concrete Composites, 12(2), 117-136. http://dx.doi.org/10.1016/0958-9465(90)90049-4

Sgriccia, N., Hawley, M. C., \& Misra, M. (2008). Characterization of natural fiber surfaces and natural fiber composites. Composites, 39(10), 1589-1684.

Suardana, N. P. G., Piao, Y.. \& Lim, J. K. (2011). Mechanical Properties of Hemp Fibers and Hemp/PP Composites: Effects Surface Treatment. Materials Physics and Mechanics, 11, 1-8.

Vieira, C. A. B., Susisn, S. B., Freire, E. Amico., \& Zattera, A. J. (2009). Characterization of Hybrid Composites Produced with Mats Made Using Different Methods. Materials Research, 12(4), 433-436. http://dx.doi.org/10.1590/S1516-14392009000400011

\section{Copyrights}

Copyright for this article is retained by the author(s), with first publication rights granted to the journal.

This is an open-access article distributed under the terms and conditions of the Creative Commons Attribution license (http://creativecommons.org/licenses/by/3.0/). 